\title{
Knowledge and Attitude to Self-Monitoring Of Blood Pressure in a Cardiology Clinic in Nigeria.
}

\author{
Ambakederemo T.E., Ebuenyi I.D.,Jumbo J \\ Niger Delta University Teaching Hospital, Department of Internal Medicine, Okolobiri, Bayelsa ,Nigeria.
}

\begin{abstract}
:
Background: We evaluated the knowledge and attitude to Self-monitoring of blood pressure amongst adult patients in a hospital in the Niger Delta so as redirect efforts to improve patients' knowledge and attitude to self-monitoring of blood pressure.

Materials and Methods: 100 patients with essential hypertension attending the Cardiology Clinic of the Niger Delta University Teaching Hospital were recruited consecutively over a two-month period (September to November 2013). Demographic data, knowledge and attitude to Self-monitoring of blood pressure were obtained using self-administered questionnaire. Simple percentages and Chi square were used to analyze data obtained. $P<0.05$ was considered statistically significant.

Results: A total of 100 patients were studied and 54.7\% of them know about self-monitoring of Blood Pressure. 88\% of the patients agreed that self-monitoring of Blood Pressure is important. Civil servants were more likely to know about SMBP or think that it is important. Those with primary or no education were four times less likely to know about SMBP.

Conclusion: The results of our study suggest suboptimal knowledge about Self-monitoring of Blood Pressure. It is important that clinicians and health care providers intensify efforts to improve patients' knowledge about SMBP for better hypertensive management outcome.
\end{abstract}

Key words: Self-monitoring of Blood Pressure, civil servants, education.

\section{Introduction}

The importance of self-monitoring of blood pressure (SMBP) in the overall management of cardiovascular diseases has been well documented. ${ }^{1-4}$ Home blood pressure(BP) measurements are indispensable for the improvement of hypertension management in medical practice as well as for the recognition of hypertension in the population. ${ }^{3}$

According to Cappuccio et al, a meta-analysis of 18 randomized controlled clinical trials found that "self" BP monitoring at home results in better control and greater achievement of BP targets than "usual" BP monitoring in the healthcare system. ${ }^{4}$ Self-monitoring has several advantages over clinic measurements-by allowing multiple readings averaged over time and by taking measurements in people's usual environment, a more reproducible BP value is produced that is devoid of the white coat and placebo effects ${ }^{5}$. BP control in people with hypertension (assessed in the clinic) and the proportion achieving targets are increased when home $\mathrm{BP}$ monitoring is used rather than standard BP monitoring in the healthcare system. ${ }^{4}$

Studies posit that home BP measurements brings an improvement of the accuracy of screening for hypertension, improves drug compliance, increases accurate assessment of BP control during treatment, involves patient in their care and reduce the need for patients to attend their general practitioner if BP is adequately controlled. ${ }^{1,3}$ However, according to O'Brien et al, only few of the devices available on the market are accurate ${ }^{5}$. Hence, standardization and validation of home BP appliances are essential in order to ensure accurate results. ${ }^{1,3,4,5}$. Studies posit a relationship between SMBP and age, socio-economic status and education.6

Knowledge of SMBP is still sub-optimal in most developing countries ${ }^{2}$. The aim of this study is to access the knowledge and attitude to SMBP by patients.

\section{Methodology}

100 patients with essential hypertension attending the medical outpatient clinic of the Niger Delta University Teaching Hospital were recruited consecutively over a two-month period. Consent was obtained from the hospital ethical committee and the patients. Newly diagnosed patients were excluded. Patients were assessed with self-administered questionnaires to obtain information about their age, time since diagnosis, type of hypertension treatment and then knowledge and use of self BP monitoring devices for monitoring of their BP. The data obtained was analyzed using SPSS version-17 for Windows. 
Knowledge and Attitude to Self-Monitoring Of Blood Pressure in a Cardiology Clinic in Nigeria.

\section{Demographics}

\section{Results}

One hundred and six patients were enrolled for the study consisting of 53 males $(50.0 \%)$ and 53 females (50.0\%). Males (median age-61, interquartile range (IQR) 29-83) were older than females (51, IQR, 2983). The demographic data of all study participants in relation to SMBP are summarized in table 1 below.

Table 1: Demographic Data

\begin{tabular}{|c|c|c|c|}
\hline S/No & Variable & Total N (\%) & 95\% C.I \\
\hline 1. & $\begin{array}{l}\text { Gender } \\
\text { Male } \\
\text { Female }\end{array}$ & $\begin{array}{l}53(50) \\
53(50) \\
\end{array}$ & $\begin{array}{l}40.1-59.9 \\
40.1-59.9 \\
\end{array}$ \\
\hline 2. & $\begin{array}{l}\text { Marital Status } \\
\text { Single } \\
\text { Married } \\
\text { Divorced } \\
\text { Widow }\end{array}$ & $\begin{array}{l}6(5.7) \\
90(84.9) \\
1(0.9) \\
9(8.5)\end{array}$ & $\begin{array}{l}2.1-11.9 \\
76.6-91.1 \\
0.0-5.1 \\
4.0-15.5 \\
\end{array}$ \\
\hline 3. & $\begin{array}{l}\text { Occupation } \\
\text { Artisan } \\
\text { Business } \\
\text { Civil Servant } \\
\text { Farmer } \\
\text { Clergy } \\
\text { Student }\end{array}$ & $\begin{array}{l}14(13.2) \\
19(17.9) \\
57(53.8) \\
13(12.3) \\
1(0.9) \\
2(1.9)\end{array}$ & $\begin{array}{l}7.4-21.1 \\
11.2-26-6 \\
43.8-63.5 \\
6.7-20.1 \\
0.0-5.1 \\
0.2-6-6\end{array}$ \\
\hline 4 & $\begin{array}{l}\text { Level of Education } \\
\text { None } \\
\text { Primary } \\
\text { Secondary } \\
\text { Tertiary }\end{array}$ & $\begin{array}{l}4(4.0) \\
23(23.2) \\
25(25.3) \\
47(47.5)\end{array}$ & $\begin{array}{l}1.1-10.0 \\
15.3-32.8 \\
17.1-35.0 \\
37.3-57.8\end{array}$ \\
\hline
\end{tabular}

\section{Knowledge and attitude to Self-Monitoring of Blood Pressure}

$58(54.7 \%)$ of the patients know about self-monitoring of BP. $28(35.9 \%)$ of the patients own a private BP meter and 88(88\%) agreed that self-monitoring of BP is important. 14(41.2\%) of those who own a selfmonitoring BP device agreed that it has been compared with a mercury sphygmomanometer. Majority of those who know $(62.1 \%)$ about SMBP, think that SMBP is important $(56.8 \%)$ and own $(60.7 \%)$ a BP machine were civil servants. Those with primary or no education were four times less likely to know about SMBP. Secondary or tertiary education were significantly associated with knowing $(\mathrm{p}=0.002)$ about SMBP or owning $(\mathrm{p}=0.035)$ BP machine. Other data on knowledge and attitude to SMBP are summarized in table 2 below.

Table 2: Knowledge and Attitude to Self-monitoring of Blood Pressure

\begin{tabular}{|l|l|l|l|l|}
\hline S/No & Variable & $\begin{array}{l}\text { Know about S.M.BP } \\
\text { N }(\%)\end{array}$ & $\begin{array}{l}\text { Think that S.M.BP is } \\
\text { important N }(\%)\end{array}$ & $\begin{array}{l}\text { Own a BP machine } \\
\text { N }(\%)\end{array}$ \\
\hline 1. & Gender & $29(50.0)$ & $43(48.9)$ & $15(37.5)$ \\
& Male & $29(50.0)$ & $45(51.1)$ & $13(53.6)$ \\
\hline 2. & Female & $5(8.6)$ & & \\
& Occupation & $13(22.4)$ & $9(10.2)$ & $1(3.6)$ \\
& Artisan & $36(62.1)$ & $50(56.8)$ & $7(25.0)$ \\
& Business & $3(5.2)$ & $11(12.5)$ & $17(60.7)$ \\
& Civil Servant & $0(0.0)$ & $0(0.0)$ & $2(7.1)$ \\
& Farmer & $1(1.7)$ & $2(2.3)$ & $0(0.0)$ \\
& Clergy & & $1(3.6)$ \\
& Student & & & \\
& & $8(29.6)$ & $20(23.8)$ & $3(11.5)$ \\
& Level of Education & $46(63.9)$ & $64(76.2)$ & $23(88.5)$ \\
\hline
\end{tabular}

\section{Discussion}

This study was undertaken to access knowledge and attitude of patients towards self-monitoring of blood Pressure. 54.7\% of the patients knew about SMBP but only 35.9\% of the population owned a personal BP machine. This value is higher than $17.72 \%$ in the study by Lau et al on self-monitoring of BP among elderly hypertensive patients ${ }^{6}$ but less than $47.5 \%{ }^{7}$ and less than $50 \%{ }^{8}$ recorded by similar studies. It is important to note the $18.8 \%$ difference in knowledge and ownership or actual practice of SMBP. This is because, ownership of a BP machine reinforces the practice of SMBP. Hence, several studies posit that most patients depend on patent medicine dealers, nurses and pharmacist for home monitoring of blood pressure ${ }^{6,8,9}$ and this accounts for about $37.5 \%{ }^{10}$ and $67.2 \%{ }^{11}$ of SMBP practices in patients . 
Majority of those who know (62.1\%) about SMBP, think that SMBP is important $(56.8 \%)$ and own $(60.7 \%)$ a BP machine were civil servants. This correlated with similar studies which showed that higher socioeconomic status and higher level of education were associated with better practice of SMBP. ${ }^{2,6,7,8,9,10}$. This relationship is worrisome especially in developing countries and other resource poor settings where optimal hypertension management may be hampered by economic factors.

Similarly, our study showed that secondary and tertiary education were significantly associated with knowing about SMBP and owning a personal BP machine. This result is strongly corroborated by similar studies which recorded a significant relationship between knowledge about SMBP and higher education status.

Our findings also show that $88 \%$ of the patient's agreed that SMBP is important in optimal management of hypertension as stated in most studies. ${ }^{1-12}$ More so, only $41.2 \%$ of the respondents agreed that there personal BP machine has been compared with a mercury sphygmomanometer The importance of this validation is widely recommended for accurate measurement of blood pressure. ${ }^{1,3,4,5}$

\section{Conclusion}

Knowledge about SMBP at the cardiology clinic of Niger Delta University teaching hospital is $54.7 \%$. Civil servants and those with tertiary or secondary education were more likely to know about SMBP or own a personal BP machine. $88 \%$ of the patients agreed that SMBP is important.

It is important that clinicians and health care providers intensify efforts that would improve patients' knowledge about SMBP and ownership of personal BP machine for better hypertensive management outcome.

\section{Recommendations}

It will be important to obtain information about the type of blood pressure monitoring device hypertensive patients who practice SMBP use; how often they check their blood pressure and their source of information about SMBP.

\section{References}

[1]. Kerry S, Markus H, Khong T, Doshi R, Conror R, Oakeshott P. Community based trial of home blood pressure monitoring with nurse-led telephone support in patients with stroke or transient ischaemic attack recently discharged from hospital. Trials 2008 , 9:15doi:10.1186/1745-6215-9-15.[internet]Available from:http://www.trialsjournal.com/content/9/1/15 Assessed on April 6, 2014

[2]. Victor O. Adika, P.P.K. Joffa and Franco A. Apiyanteide. Hypertension Knowledge among Non-Academic Employees of Niger Delta University, Bayelsa State, Nigeria. International Journal of Tropical Medicine 2011, 6: 113-120

[3]. Imai Y, Otsuka K, Kwano Y, Shimada K, Hayashi H, Tochikubo O, Miyakawa M, Fukiyama K. Japanese Society of Hypertension (JSH) Guidelines for Self-Monitoring of Blood Pressure at Home. Hypertens Res 2003; Vol. 26: No. 10

[4]. Cappuccio F P, Kerry S M, Forbes L, Donald A. Blood pressure control by home monitoring: meta-analysis of randomized trials. BMJ June 2004, doi:10.1136/bmj.38121.684410.AE

[5]. O’Brien E, Asmar R, Beilin L, Imai Y, Mancia G, Mengden T, et al on behalf of the European Society of Hyperten sion working group on blood pressure monitoring. European Society of Hypertension recommendations for conventional, ambulatory and home blood pressure measurement. J Hypertens 2003; 21:821-48.

[6]. Lau E, Kaczorowski J, Karwalajtys T, Dolovich T, Levine M, Chambers L. Blood Pressure Awareness and Self-Monitoring Practices among Primary Care Elderly Patients. Canadian Pharmacists Journal / Revue des Pharmaciens du Canada November/December 2006 vol. 139 no. 6 34-4. doi: 10.1177/171516350613900607. [internet]Available from: http://cph.sagepub.com/content/139/6/34.abstract. Assessed on April 6, 2014

[7]. Baghianimoghadam M.H, Rahaee Z, Morowatisharifabad M.A, Sharifirad G, Andishmand A, Azadbakht L. Effects of education on self-monitoring of blood pressure based on BASNEF model in hypertensive patients. J Res Med Sci. 2010 Mar-Apr; 15(2): 70-77. [internet]Available from: http://www.ncbi.nlm.nih.gov/pmc/articles/PMC3082790/. Assessed on April 6, 2014

[8]. Lam JY, Guirguis LM. Patients' blood pressure knowledge, perceptions and monitoring practices in community pharmacies. [internet]Available from: http://www.pharmacypractice.org/journal/index.php/pp/article/view/107. Assessed on April 6, 2014

[9]. Jones M.I, Greenfield SM, Bray EP, Hobbs FR, Holder R, Little P, Mant J, Williams B, McManus RJ Patient self-monitoring of blood pressure and self-titration of medication in primary care: the TASMINH2 trial qualitative study of health professionals' experiences. $\mathrm{Br}$ J Gen Pract. 2013 Jun; 63(611):e378-85. doi: 10.3399/bjgp13X668168. [internet]Available from: http://www.ncbi.nlm.nih.gov/pubmed/23735408. Assessed on April 6, 2014

[10]. Huanhuan Hu, Gang Li, and Takashi Arao, "Prevalence Rates of Self-Care Behaviors and Related Factors in a Rural Hypertension Population: A Questionnaire Survey," International Journal of Hypertension, vol. 2013, Article ID 526949, 8 pages, 2013. doi:10.1155/2013/526949. [internet]Available from: http://www.hindawi.com/journals/ijhy/2013/526949/. Assessed on April 6, 2014.

[11]. Faronbi J.O, Oladepo R.O, Faronbi G.O, Olaogun A.A. Blood Pressure Monitoring Practices and Health Seeking Behaviors' among University Staff in Nigeria. International Journal of Caring Sciences January-April 2014 Vol 7

[12]. Halme L, Vesalainen R, Kaaja M, Kantola I; HOme MEasuRement of blood pressure study group. Self-monitoring of blood pressure promotes achievement of blood pressure target in primary health care. Am J Hypertens. 2005 Nov; 18(11):1415-20. [internet]Available from: http://www.ncbi.nlm.nih.gov/pubmed/16280273.Assessed on April 6, 2014. 